Open access to Pharmaceutical and Medical research

(C) 2014, publisher and licensee JDDT, This is an Open Access article which permits unrestricted noncommercial use, provided the original work is properly cited

\title{
ISOLATION AND CHARACTERIZATION STUDIES OF MUCILAGE OBTAINED FROM TRIGONELLA FOENUM GREACUM L. SEED AND TAMARINDUS INDICA POLYSACCHARIDE AS A PHARMACEUTICAL EXCIPIENT
}

\author{
Verma Shubham*, Bansal Jharna, Kumar Nitin, Malviya Rishabha, Sharma Pramod Kumar
}

Department of Pharmacy, School of Medical and allied sciences, Galgotias University, Greater Noida, U. P. (India)

\begin{abstract}
:
Now-a-days natural or herbal products are more often used in comparison to synthetic products because of its low toxicity, biodegradability, biocompatibility and its cheaper cost. The main aim of this study is to isolate and characterize mucilage obtained from Trigonella foenum graecum $L$. seed and Tamarindus indica polysaccharide as pharmaceutical excipients. Both isolated mucilages are extracted by different methods i.e., hot water extraction method and reflux method respectively. Ethyl alcohol is used in the isolation of mucilages. Solubility behaviour of isolated mucilages with different solvents was also studied. Different phytochemical characterization of isolated mucilages were studied like bulk and tapped densities, compressibility index, hausner's ratio and swelling index etc. and some identification tests were also carried out for presence of carbohydrate, fats, oils etc.
\end{abstract}

Keywords: Methi, tamarind, extraction, mucilage, excipients

\section{INTRODUCTION:}

Nature has gifted us with great and different varieties of flora and fauna. From the earliest centuries human has made effective use of the natural or herbal origin in the pharmaceutical field. Natural products are more often used in comparison to synthetic products ${ }^{1-2}$. Herbal or natural products are used because of its low accessibility, biocompatibility, low cost and its less toxic effects. Mucilages and gums obtained from natural sources are most widely used as pharmaceutical excipients for their different properties such as its binding, diluents and disintegrant properties in tablets, suspending, gelling properties in gel, thickening properties in oral liquids etc. In novel drug delivery formulations there are increased use of herbal products to provide less toxic and more effective dosage form. Many researchers have explored the utility of natural or herbal materials as pharmaceutical excipients. Majority of investigations on natural polymer in novel drug delivery system are centered on proteins and polysaccharides because of their ability to produce broad range of materials and its properties ${ }^{3-4}$.

The seeds of Trigonella foenum graecum $L$. are also known as fenugreek seed or Methi in Hindi. It is an herbaceous plant of leguminaceae or fabaceae family. The seeds of Trigonella foenum graecum L. are also used as vegetables and also functions as a preservative and added to pickles. The riped fenugreek seeds have some medicinal use such as in treatment of dysentery, dyspepsia, enlargement of liver, diabetes and chronic cough $^{5-6}$.
Under the category of polysaccharide, various natural gums are covered like acacia, karaya and tragacanth gum etc. Gums are used as a binder in tablets, thickeners in cosmetic manufacturings. Tamarindus indica also known as imli in Hindi and belongs to Leguminaceae family. The part used to extract the polysaccharide is seeds of Tamarindus indica. The main component of Tamarindus indica seed has been found as a non-ionic, neutral, branched polysaccharide which consists of a celluloselike backbone that carries xylose and galactoxylose substituents ${ }^{7}$.

\section{MATERIALS AND METHODS:}

The Trigonella foenum graecum seeds were procured from local market of Greater Noida, India and the seeds of Tamarindus indica was obtained as a waste material from local grocery shop of Noida, India. All other chemicals are used of analytical grade.

2.1. Extraction of Trigonella foenum graecum L. Seed: Trigonella foenum graecum seeds was extracted by hot water extraction method in which seeds were washed with water and dried at room temperature. The seeds were placed in water and then boiled it for $12 \mathrm{hrs}$ at $45^{\circ} \mathrm{C}$ for release of mucilage into water. The material was then squeezed in a muslin cloth to remove the marc from the filtrate. The filtrate was then kept in refrigerator for cooling ${ }^{8}$.

*Address for correspondence: Shubham Verma,

Department of Pharmacy, School of Medical and allied sciences, Galgotias University, Greater Noida, U. P. (India). Contact: 09451407296, E-mail:- shubh.verma678@gmail.com 
2.2. Extraction of Tamarindus indica seed polysaccharide: Tamarind seed polysaccharide was extracted under reflux in a condensation system using water as solvent. Temperature of extraction media was maintained at $70^{\circ} \mathrm{C}$ and duration of extraction was adjusted about $6 \mathrm{~h}$. The extractor thimble was a Whattman cellulose thimble with $33 \mathrm{~mm}$ internal diameter and $80 \mathrm{~mm}$ external length ${ }^{9-}$ 10 .

2.3. Isolation of Trigonella foenum graecum $L$. mucilage \& Tamarindus indica polysaccharide: Equal volume of ethyl alcohol was added to filtrate to precipitate the mucilage, the mucilage was separated, dried in oven at about $50^{\circ} \mathrm{C}$ and powdered it. The powdered mucilage was stored in a air tight container ${ }^{9-10}$.

\section{PHYSICOCHEMICAL CHARACTERIZATION OF ISOLATED MUCILAGES:}

3.1. Organoleptic evaluation of isolated mucilage: The isolated mucilage was characterized for organoleptic properties such as color, odor, fracture and texture ${ }^{11-12}$.

3.2. Identification tests for carbohydrate, fat, gum and mucilage: Aqueous solution of extracted mucilage was used for chemical characterization. Tests for carbohydrate, gums, fat and mucilage were performed according to standard procedure. Test for carbohydrate shows positive result and other tests like presence of tannins, oils and fats in isolated mucilage shows negative results.

3.3. pH of mucilages: The mucilage was weighed and dissolved in water to get a $1 \% \mathrm{w} / \mathrm{v}$ solution. The $\mathrm{pH}$ of solution was determined using digital $\mathrm{pH}$ meter ${ }^{13}$.

3.4. Swelling index of isolated mucilages: The swelling characteristics of Trigonella foenum graecum $L$. and
Tamarindus indica seed mucilages were tested in distilled water. The swelling index is the volume in ml occupied by 1 gm of the substance. The swelling indices of the selected mucilages were determined by accurately weighing $1 \mathrm{gm}$ of mucilages, which was further introduced into a $25 \mathrm{ml}$ glass stoppered measuring cylinder then $25 \mathrm{ml}$ of distilled water was added and the mixtures were shaken thoroughly every $10 \mathrm{~min}$ for $1 \mathrm{hr}$ and then allowed to stand for $24 \mathrm{hr}$ at room temperature. The volumes occupied by the mucilages were measured. The procedure was repeated thrice and then the mean values were calculated ${ }^{14}$.

3.5. Bulk \& Tapped densities: The pre-weighed quantities of mucilages were poured in graduated cylinders and the volume was recorded. Then the powder was subjected to tapping in a bulk density apparatus until constant volume were obtained ${ }^{15}$.

3.6. Powder compressibility and Hausner's ratio: Powder compressibility is also known as Carr's index. Carr's index and Hausner's ratio were calculated from the bulk and tapped densities ${ }^{10}$.

3.7. Powder flow property: It is also known as angle of repose. The angle of repose was determined by the fixed height funnel method ${ }^{10}$.

\subsection{Infrared spectra of the isolated mucilages:}

Hundred milligrams of the powdered pectin was mixed with potassium bromide (400 $\mathrm{mg}$ ) and was compressed in a hydraulic press to form a pellet at 15 tons pressure. The pellets were scanned from 4000 to $400 \mathrm{~cm}^{-1}$ in Bruker FTIR spectrophotometer for Methi and in Shimadzu FTIR spectrophotometer for Tamarind ${ }^{9}$.

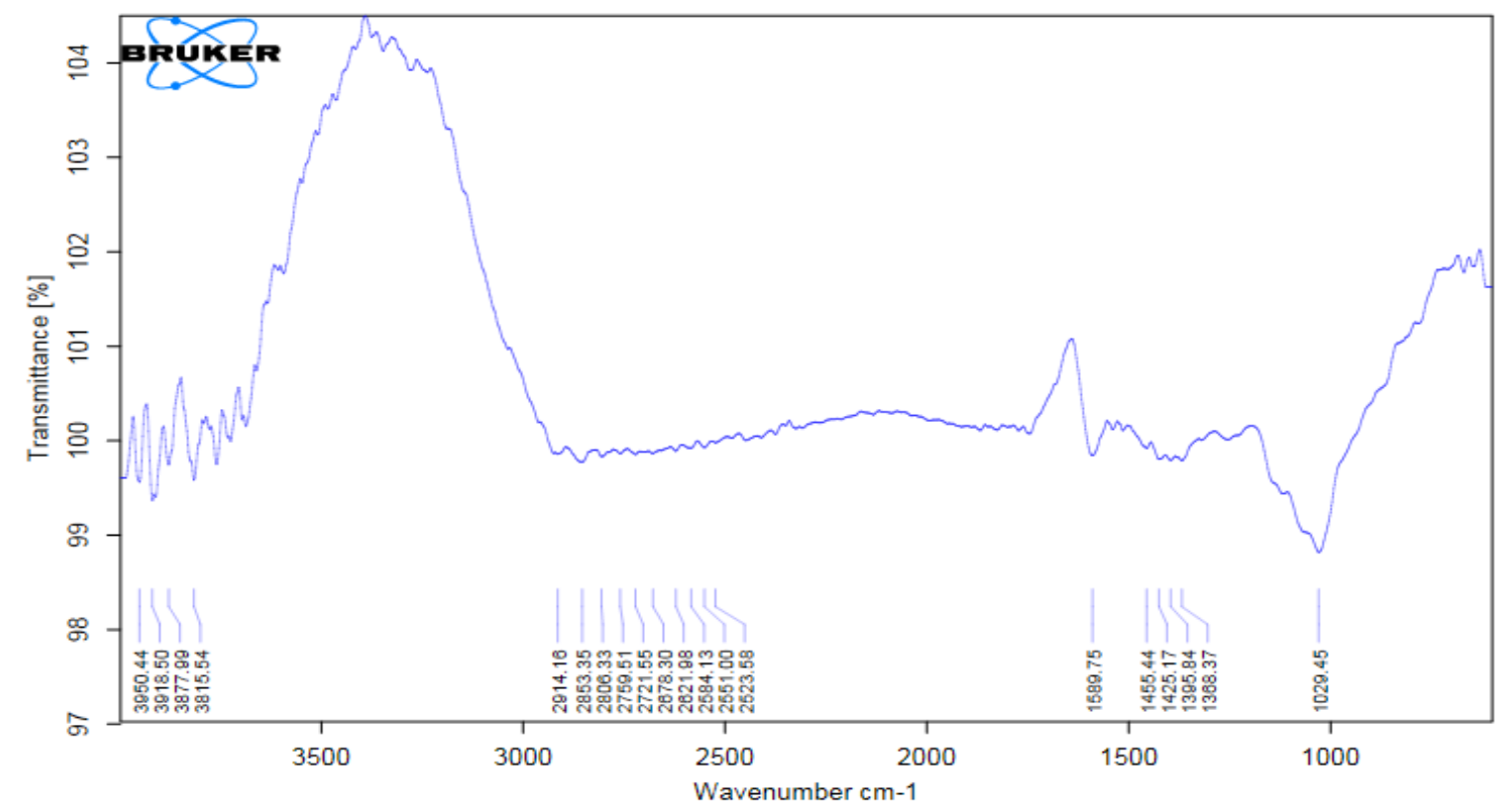

Figure 1: FTIR Spectroscopy of Trigonella foenum graecum $L$.

\begin{tabular}{|c|c|}
\hline Frequency $\left(\mathbf{c m}^{-1}\right)$ & Assignment \\
\hline 3654 & O-H stretch \\
\hline 2914.16 & C-H \\
\hline 2853.35 & C-H \\
\hline 2621.98 & C $=$ C \\
\hline 1425.17 & C-H Bend \\
\hline 1368.37 & C-H Rock \\
\hline 1029.45 & C-H Bend out of plane \\
\hline
\end{tabular}




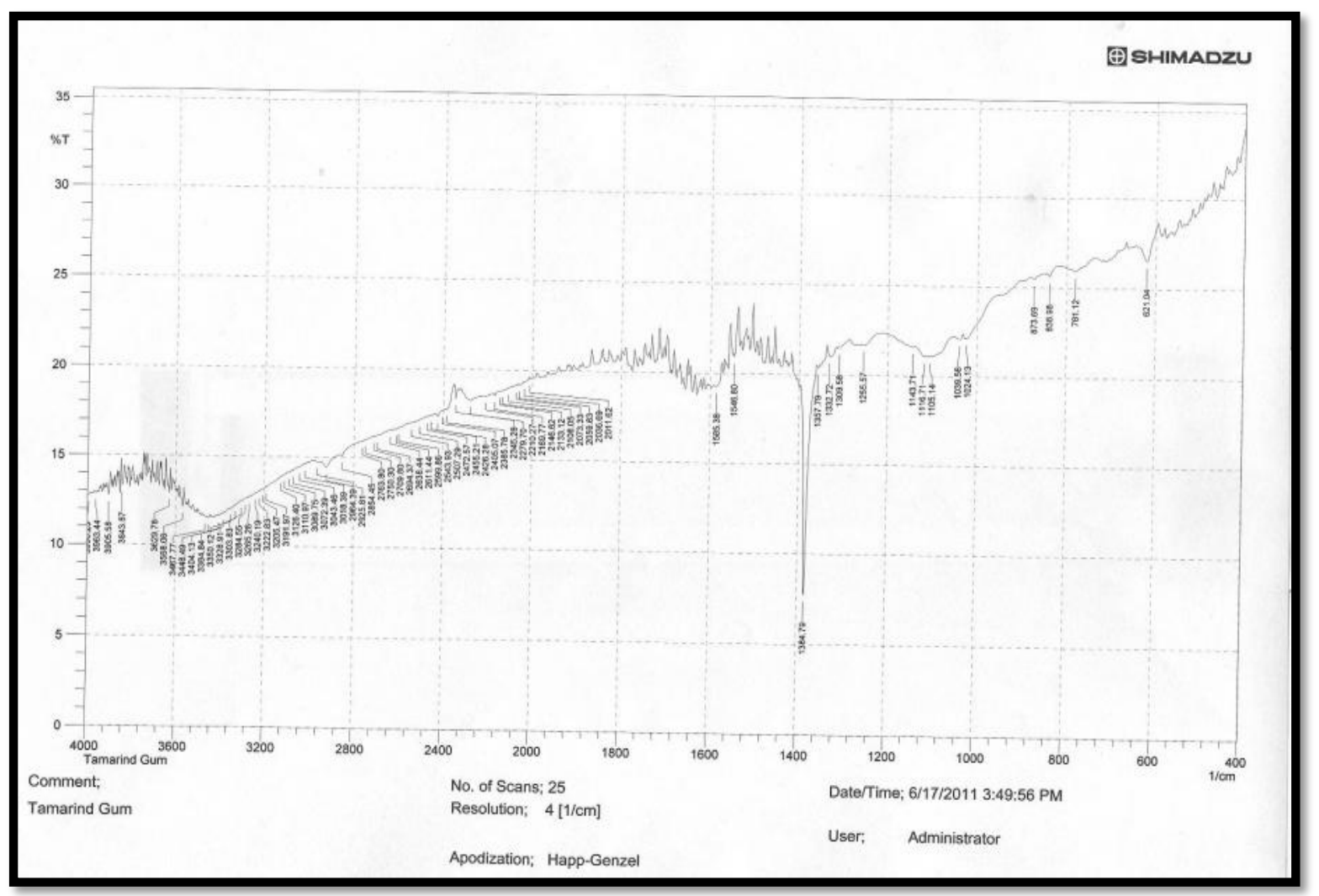

Figure 2: FTIR Spectroscopy of Tamarindus indica

\begin{tabular}{|c|c|}
\hline Frequency $\left(\mathbf{c m}^{-\mathbf{1}}\right)$ & Assignment \\
\hline 3645.87 & O-H Stretch \\
\hline 3508.70 & O-H Stretch \\
\hline 2925.81 & C-H Stretch \\
\hline 1505.80 & N-O asymmetric stretch \\
\hline 1384.79 & C-H rock \\
\hline 1332.72 & C-H bend \\
\hline
\end{tabular}

\section{RESULTS AND DISCUSSION:}

Trigonella foenum graecum L. and Tamarindus indica were isolated and then subjected to identification. Isolated mucilage also showed presence of carbohydrates and remaining phytoconstituents such as tannins and fats were absent. This result considered as a proof for purity of isolated mucilage.

The organoleptic properties of the isolated mucilages were depicted in table 1 in which colors of both isolated mucilages were found to be light brown with characteristic odor.

Table1: Organoleptic properties of isolated mucilages

\begin{tabular}{|l|l|l|}
\hline Parameter & Fenugreek & Tamarind \\
\hline Color & Light Brown & Light Brown \\
\hline Odor & Odorless & Odorless \\
\hline Taste & Tasteless & Tasteless \\
\hline Fracture & Rough & Rough \\
\hline Texture & Rough \& Irregular & Rough \& Irregular \\
\hline
\end{tabular}

The $\mathrm{pH}$ of both isolated mucilages (Trigonella foenum graecum L. and Linum usitatissimum) was found to be $7.9 \& 6.1$ respectively and both mucilages have good flow property. Micromeretic studies of isolated mucilages like bulk density, tapped density, Carr's index etc were carried out and depicted in table2. The solubility behavior of both mucilages were carried out using different solvents by which it was found that both isolated mucilages are soluble in hot water and swells to form gel in cold water and both isolated mucilages are insoluble in acetone, ethyl alcohol, methanol and chloroform.

Table2: Micromeritic studies of isolated mucilages

\begin{tabular}{|l|c|c|}
\hline \multirow{2}{*}{\multicolumn{1}{|c|}{ Parameters }} & \multicolumn{2}{c|}{ Results } \\
\cline { 2 - 3 } & Fenugreek & Tamarind \\
\hline Bulk density $(\mathrm{gm} / \mathrm{ml})$ & $0.66 \pm 0.043$ & $0.63 \pm 0.03$ \\
\hline $\begin{array}{l}\text { Tapped } \\
\text { density }(\mathrm{gm} / \mathrm{ml})\end{array}$ & $0.94 \pm 0.098$ & $0.83 \pm 0.04$ \\
\hline Yield $(\%)$ & 15.16 & - \\
\hline Bulkiness $(\mathrm{ml} / \mathrm{gm})$ & $1.48 \pm 0.099$ & $1.58 \pm 0.072$ \\
\hline Carr's index & $28.2 \pm 3.11$ & $24.17 \pm 1.20$ \\
\hline Hausner's ratio & $1.39 \pm 0.057$ & $1.03 \pm 0.07$ \\
\hline Ash Value(\%) & 1.02 & 0.56 \\
\hline Water-soluble Ash & 0.68 & 0.42 \\
\hline Acid-soluble Ash & 0.56 & 0.30 \\
\hline pH & 7.9 & 6.1 \\
\hline Angle of repose $\left({ }^{\circ}\right)$ & 29.20 & 29.45 \\
\hline Swelling index $(\%)$ & 90 & 90 \\
\hline
\end{tabular}




\section{CONCLUSION:}

From the above study, we conclude that Trigonella foenum graecum $L$. and Tamarindus indica seed mucilages can be used as a pharmaceutical excipients to prepare different dosage forms. Tamarindus indica had a rich source of polysaccharide in comparison to Trigonella foenum graecum $L$. and both isolated mucilages showed good flow property.

\section{REFERENCES:}

1) Robbin SRJ, Gum arabic: A review of recent trends in selected markets for watersoluble gums, ODNRI Bulletin, 1988, 108, 18-33.

2) Patel DM, Prajapati DG, Patel NM, Seed mucilage from Occimum americanum Linn. as disintegrant in tablets: Seperation and Evaluation, Indian J Pharm Sci, 2007, 69(3), 431-435.

3) Razavi SMA, Mortazavi SA, Merino LM, Parvar SHH, Motamedzadegan A, Khanipour E, Optimization study of gum extraction from Basil seeds (Ocimum basilicum L.), International Journal of Food Science and Technology, 2009, 44, 1755-1762.

4) Sheth NS, Shah NV, Shah NC, Extraction of mucilage from Occimum americanum Linn and its role as disintegrant in tablets formulation, Journal of Global Pharma Technology, 2010, 2(12), 26-31.

5) Petropoulos GA. Botany- Fenugreek: The genus Trigonella. London: Taylor and Francis; 2002. P. 9-17.

6) Abdul-barry JA, Abdul-Hassan IA, Al-Hakein MA, Hypoglycemic and antihyperglycemic effects of Trigonella Foenum-graceum leaf in normal and alloxan induced diabetic rats, J Ethnopharmacol, 1997, 58, 149-155.

7) Soumendr S, Rashmirekha S, Padma LN, Tamarind Seed Polysachharide, A versatile biopolymer for mucoadhesive applications, JPBMS, 2011, 8, 1-12.

\section{ACKNOWLEDGEMENT:}

Authors are highly thankful to Department of Pharmacy, School of Medical and Allied Sciences, Galgotias University, Greater Noida India for providing library facility during literature survey.

Conflict of interest: Authors have no conflict of interest.

8) Harborne JB. Sugars and their derivatives. In: Phytochemical methods: A guide to modern techniques of plant analysis. $3^{\text {rd }}$ ed. London: Chapman \& Hall; 1998. p. 235-290.

9) Malviya R, Srivastava P, Bansal M, Sharma PK, Mango Peel Pectin as Superdisintegrating Agents, Journal of Scientific and Industrial Research 2010, 69, 688-690.

10) Malviya R, Extraction and characterization of selected mucilage as a pharmaceutical excipients, Polim Med, 2011, 3, 39-44.

11) Kokate CK, Purohit AP, Gokhale SB. Pharmacognosy. $24^{\text {th }}$ ed. Pune: Nirali Prakashan; 2003. p. 109.

12) Indian Pharmacopoeia. Ministry of health and family welfare, Govt. of India. $4^{\text {th }}$ ed. New Delhi. Controller of publications. 1996. p. A-54,

13) Lala PK. Practical Pharmacognosy. Calcutta: Lina Guha; 1981. p. 135.

14) Bal T, Murthy PN, Sengupta S, Isolation and analytical studies of mucilage obtained from the seeds of Dillenia indica (family dilleniaceae) by use of various analytical techniques, Asian journal of pharmaceutical and clinical research, 2012, 5(3), 65-67.

15) Pabon CV, Frutos P, Lastres JL, Frutos G, In-vitro study of mixed controlled release matrix tablets containing HPMC and polyamide, Drug Develop Ind Pharm, 1992, 18(20), 21632171. 